\title{
Procalcitonin levels in patients with suspected sepsis
}

\author{
Tribeni Goswami', Renu Mathew², Marina Thomas ${ }^{3}$, Reena Anie Jose ${ }^{4}$, Anjali Jacob ${ }^{5}$, \\ Sherin Susan Abraham ${ }^{6}$ \\ ${ }^{1,5,6}$ Assistant Professor, ${ }^{2}$ Professor and Head, ${ }^{3}$ Professor, ${ }^{4}$ Associate Professor, Department of Microbiology, Believers \\ Church Medical College Hospital, Thiruvalla, Kerala, India
}

Background: Procalcitonin (PCT) was found to be a valuable and reliable biomarker for sepsis, especially in critical care patients for whom early recognition and prompt treatment could reduce mortality. Aims and Objectives: This study was aimed at correlating the levels of PCT as diagnostic marker for sepsis in relation to the culture positivity of various samples from blood, respiratory, urine, and exudates from patients admitted in a tertiary care hospital. Materials and Methods: Results of PCT level along with bacterial culture results of blood, respiratory, urine, and exudates were analyzed from 780 patients for a period of 1 year. Results: High PCT values ranging from 0.52 to $200 \mathrm{ng} / \mathrm{ml}$ were found in 331 patients admitted with suspected sepsis. Out of 135 cases of sepsis, 85 had blood culture positivity alone and 50 had culture positivity in blood and in other sites with the same organism. Among the 85 cases of bloodstream infections, in which no localized infections were identified, the median PCT was 33 for Gram-negative bacteremia, which was significantly higher as compared with a median of 16 for Gram-positive cocci. In UTI with bacteremia, the median PCT was 45.34 and in UTI without bacteremia, it was 5. Conclusion: From this study, we concluded that PCT values may be useful to distinguish Gram-negative and Gram-positive bacteremia, and furthermore, a high PCT value for patients with UTI may be helpful in predicting bacteremia.

Key words: Procalcitonin; Sepsis; Bacteremia; Urinary tract infections; Gram-negative bacilli

\section{INTRODUCTION}

Sepsis is a serious condition and still a common cause of morbidity and mortality worldwide. Bacteremia is identified only in a proportion of patients who present with sepsis and bloodstream infections even when microbiological diagnostic methods are available. ${ }^{1}$ Isolation, identification, and antimicrobial susceptibility testing of the bacteria causing bacteremia are achieved by performing blood cultures, which is the gold standard for confirmation of bacteremia. However, the inadvertent delay of blood culture reports emphasizes the need for an earlier diagnosis of sepsis. ${ }^{2}$ All patients who appear septic do not demonstrate an infection, and the widespread administration of antibiotics to all these patients carries problems of developing antibiotic resistance, drug toxicity, and increased medical cost. Hence, there is a need for an effective and accurate biochemical marker to support or exclude the diagnosis of infection. ${ }^{3}$

Procalcitonin (PCT), a precursor molecule of calcitonin, was found to be a valuable and reliable biomarker for sepsis in comparison to interleukin-6 (IL-6) and C-reactive protein (CRP) for early diagnosis of sepsis, especially in critical care patients, where early recognition and prompt treatment can reduce morbidity and mortality. ${ }^{4}$

PCT is produced by thyroid C cells, coded by a CALC-1 gene located on chromosome 11 in healthy individuals. The PCT formed in thyroid C cells is converted to calcitonin so that PCT is not released into the circulation and its level in 
serum is very low $(0.05 \mathrm{ng} / \mathrm{mL})$. During inflammation, the release of PCT is independent of the above regulation and is produced mainly by two alternative mechanisms; direct pathway induced by lipopolysaccharide (LPS) or other toxic metabolite from microbes and indirect pathway induced by various inflammatory mediators such as IL-6 and tumor necrosis factor-alpha. ${ }^{5}$

The levels of PCT in sputum and serum elevate after $3-6 \mathrm{~h}$ of inflammation and reach to its highest peak at $<6-8 \mathrm{~h}$, following a pattern similar to that of acute bacterial infection. ${ }^{6}$

This study was designed as an observational study with the objective of correlating the levels of PCT as a diagnostic marker of sepsis in relation with culture positivity of various samples such as blood, respiratory, urine, and exudates from patients admitted in a tertiary care hospital.

\section{Aims and objectives}

To correlate the levels of PCT as a diagnostic marker of sepsis in relation with culture positivity of various samples like blood, respiratory, urine and exudates from patients admitted in a tertiary care hospital.

\section{MATERIALS AND METHODS}

This was a cross-sectional study conducted in the department of microbiology in a tertiary care hospital in South India.

Ethical approval for the study was obtained from the Institutional Ethics Committee (IEC No:/2020/02/124).

\section{Inclusion criteria}

All adult ( $>18$ years) patients admitted in the intensive care unit of our hospital who had suspected sepsis or infection in other sites were included in this study.

\section{Exclusion criteria}

Patients with a history of trauma, surgical procedures, and with medullary carcinoma of thyroid were excluded from this study.

\section{Methodology}

A total number of 780 patients were studied during a period of 1 year (January 1, 2019-December 31, 2019).

PCT level was assayed along with bacterial cultures of blood, respiratory, urine, and exudates according to the indication.

\section{Sample collection and processing}

Paired blood culture samples (5-10 $\mathrm{ml}$ each) were collected in Bac-T/Alert bottles from two noncontinuous veins with strict aseptic precautions in all suspected cases of sepsis.

Respiratory samples such as sputum, bronchoalveolar lavage, and endotracheal aspirate, exudate samples such as pus, pus swabs, tissue and aspirated body fluids, and urine samples were collected in appropriate sterile containers for bacterial culture depending on the clinical indication. Samples were processed in the microbiology laboratory without any delay, as per the standard procedure and identification of the bacterial isolates were carried out by conventional or Vitek- 2 compact system. ${ }^{7}$ UTI with bloodstream infections was further divided into upper and lower urinary tract infections (UTIs) based on clinical presentation.

Two milliliters of clotted blood sample were collected in Gel tube for serum PCT assay. PCT level was determined by automated enzyme-linked fluorescent assay in VIDAS of BioMerieux. Any value of PCT above $0.5 \mathrm{ng} / \mathrm{ml}$ was considered as high. ${ }^{8,9}$ PCT levels in serum were tested within $72 \mathrm{~h}$ of the culture being sent to the microbiology laboratory.

Results of PCT and bacterial cultures of different samples obtained were analyzed to find out correlation between levels of PCT and culture positivity. Data collected through the Google Forms were exported into Google Sheets first and then transported to Microsoft Excel 2016 for further analysis of median calculation for each group. Results were expressed as median values.

\section{RESULTS}

The total number of patients included in this study was 780 where PCT was done along with cultures of various samples. High PCT values ranging from 0.52 to $200 \mathrm{ng} / \mathrm{ml}$ were found in 331 patients admitted with suspected sepsis.

Blood culture was done in 650 patients, of which $135(20.76 \%)$ patients had bacteremia and 515 (79.23\%) were without bacteremia. Out of 135 cases of sepsis, blood culture alone was positive in 85 cases and 50 had culture positivity in blood as well as from other sites with the same organism.

In 50 patients, bacteremia was associated with infections in other sites which included UTI, lower respiratory infections, and skin and soft-tissue infections with the same organism. Their numbers and the median PCT values are given in Table 1.

The type of microorganism isolated in bloodstream infections along with the median PCT value is shown in Table 2. 


\begin{tabular}{|c|c|c|}
\hline Infections & Number & Median PCT value \\
\hline Bacteremia alone & 85 & 28.08 \\
\hline $\begin{array}{l}\text { Urinary tract infections with } \\
\text { bacteremia }\end{array}$ & 40 & 45.34 \\
\hline $\begin{array}{l}\text { Lower respiratory infections } \\
\text { with bacteremia }\end{array}$ & 5 & 40.63 \\
\hline $\begin{array}{l}\text { Skin and soft-tissue } \\
\text { infections with bacteremia }\end{array}$ & 5 & 106 \\
\hline Total & 135 & \\
\hline
\end{tabular}

\begin{tabular}{lcc}
\multicolumn{3}{c}{ Table 2: Isolates in bloodstream infections alone } \\
Type of bacteria & Number & PCT median \\
\hline Gram-negative bacilli & 59 & 33.20 \\
Fermentative bacilli & 40 & 41.79 \\
Non-fermentative bacilli & 19 & 22.9 \\
Gram-positive bacteria & 25 & 16.6 \\
Candida species & 1 & \\
Total & 85 & \\
\hline
\end{tabular}

\begin{tabular}{lcc}
\multicolumn{3}{l}{ Table 3: Isolates from bloodstream infections } \\
with UTI & Number & Median PCT \\
\hline Isolate & 24 & 61.28 \\
\hline Escherichia coli & 10 & 23.69 \\
$\begin{array}{l}\text { Other Gram-negative bacilli } \\
\text { - Klebsiella (8) }\end{array}$ & & \\
- Enterobacter (1) & & \\
- Serratia (1) & & \\
Gram-positive cocci & 5 & \\
- MRSA (2) & & \\
- MSSA (2) \\
- Enterococci (1)
\end{tabular}

The number of different isolates from bloodstream infections associated with UTI and their median PCT values is given in Table 3 .

Out of the 40 cases of blood culture positivity with UTI, Gram-negative bacilli were isolated in 34, Gram-positive cocci were isolated in five cases and one was candidemia with candiduria for which the PCT value was 14.58. Eschericbia coli was the causative agent in 24 cases where the median PCT was 61.28.

Out of these 40 cases, 17 (42.5\%) were upper UTI and $23(57.5 \%)$ were lower UTI and their median PCT values were 51 and 21 , respectively.

Median PCT values in localized infections without bacteremia are shown in Table 4.

Further analysis was done for 100 culture-negative cases with high PCT value randomly. PCT was found to be elevated in non-infective cases such as cardiac, renal, hepatic, and pancreatic diseases.

\begin{tabular}{lcc}
$\begin{array}{l}\text { Table 4: Median PCT values in localized } \\
\text { infections without bacteremia }\end{array}$ & Number & $\begin{array}{c}\text { Median } \\
\text { PCT value }\end{array}$ \\
\hline Infections & 26 & 5 \\
& 48 & 8.31 \\
Urinary tract infections alone & 22 & 1.92 \\
Lower respiratory infections alone & 96 & \\
Skin and soft-tissue infections alone & \\
Total & 96 \\
\hline
\end{tabular}

\section{DISCUSSION}

The early detection of infections is still a challenge for clinicians. The general consensus among clinicians is to select appropriate antibiotic for every suspected infection because of emerging issues with bacterial drug resistance. Therefore, a marker specific for bacterial infection would be most helpful. ${ }^{10}$ PCT is a reliable biomarker that contributes to the early diagnosis of invasive bacterial infections and evaluation of their severity. ${ }^{11,12}$ PCT has been widely used for an early clinical diagnosis of sepsis, before the availability of blood culture results. However, bacteremia is confirmed through microbiological methods in only about $30 \%$ of patients with sepsis. ${ }^{13}$ At the same time, PCT alone has some limitations in discriminating infectious diseases as PCT levels may be elevated in non-infectious diseases also. ${ }^{14}$

In the present study, out of 135 cases of sepsis, 85 had blood culture positivity alone and 50 had culture positivity in blood and in other sites with the same organism.

Among the 85 cases of bloodstream infections, in which no localized infections were identified, the median PCT was 33 for Gram-negative bacteremia, which was significantly higher as compared with a median of 16 for Gram-positive cocci. The range of PCT level is found to be influenced by the type of bacterial isolation in our study which was in line with other studies. ${ }^{15-17}$ In comparison to Grampositive infections, elevated levels of PCT are seen in Gram-negative bacterial infections due to higher level of PCT induction which may reflect difference in interactions between Gram-positive and Gram-negative bacteria with the host cells which involves lipoteichoic acids or LPS. In Gram-positive bacterial infections, the toll-like receptor 2 pathway is activated whereas TLR4 pathway is activated in Gram-negative bacterial infections, resulting in different production of inflammatory cytokines, which ultimately stimulate ubiquitous transcription of calcitonin mRNA and release of PCT from multiple tissues other than C-cells of thyroid. ${ }^{18}$

Our finding of a higher PCT median in fermentative Gram-negative bacteremia is consistent with a study conducted by Sheng et al., who demonstrated significant 
differences in PCT levels between bloodstream infections caused by E. coli and non-fermentative Gram-negative bacilli. ${ }^{19}$ Whereas in a study done by Leng et al., there were no significant differences in PCT values among different bacterial infections. ${ }^{20}$

Among the 50 cases of bacteremia with associated localized sepsis with the same microorganism, UTI was seen in 40 cases in our study. A high median PCT value of 61.28 was seen where E. coli was the infecting organism when compared to a lower median PCT of 23.69 with other Gram-negative bacilli. Similar results were reported in a study by Watanabe et al., in bacteremia due to ESBL producers. ${ }^{21}$

A significantly higher median PCT of 51 was observed in bacteremia associated with upper UTI (pyelonephritis) when compared to that of a lower UTI (cystitis) where median PCT was 21 in our study. This finding was in concurrence with other studies. ${ }^{22,23}$

PCT values significantly varied in UTI, with and without bacteremia. In our study, in UTI with bacteremia, the median PCT was 45.34 and in UTI without bacteremia, it was 5 . This finding was in concordance with other studies also. ${ }^{24}$ Hence, a high PCT value in a patient with UTI may be helpful in predicting bacteremia.

However, PCT values assume considerable significance in suspecting bacteremia, more than that of lactate, CRP, and leukocyte estimations and therefore of great value in emergency situations. ${ }^{25}$ It is said that PCT can accurately predict the presence of bacteremia in patients with a febrile UTI. ${ }^{26}$ However, in many studies, it is shown that PCT levels may increase in non-infectious diseases conditions also. $^{27}$

\section{Limitations of the study}

The results from our study are limited by its crosssectional design and deserve to be validated in prospective longitudinal studies. Large-scale studies are needed to better define the usefulness of PCT levels in various clinical settings.

\section{CONCLUSION}

From our study, we conclude that PCT values may be helpful to distinguish Gram-negative and Gram-positive bacteremia and a high PCT value in a patient with UTI may be helpful in predicting bacteremia. The application of assays for PCT along with clinical evaluation could guide treatment and reduce unnecessary antibiotic use.

\section{ACKNOWLEDGMENT}

The authors would like to thank technical staff of Laboratory Medicine and Dr. Alice David, Head of Medical Research (Epidemiology and Biostatistics) for all the support.

\section{REFERENCES}

1. Nelson GE, Mave $V$ and Gupta A. Biomarkers for sepsis: A review with special attention to India. Biomed Res Int. 2014;2014:264351. http://doi.org/10.1155/2014/264351

2. Panday RS, Wang S, van de Ven PM, Hekker TA, Alam N and Nanayakkara PW. Evaluation of blood culture epidemiology and efficiency in a large European teaching hospital. PLoS One. 2019;14(3):e0214052.

https://doi.org/10.1371/journal.pone.0214052

3. Chan YL, Tseng CP, Tsay PK, Chang SS, Chiu TF and Chen JC. Procalcitonin as a marker of bacterial infection in the emergency department: An observational study. Crit Care. 2004;8(1):R12-R20. http://doi.org/10.1186/cc2396

4. Sharma S and Duggal N. Role of procalcitonin, II-6 and C- reactive protein in suspected cases of sepsis. Indian J Pathol Microbiol. 2019;62(4):578-581. http://doi.org/10.4103/IJPM.IJPM_762_18

5. Vijayan AL, Vanimaya, Ravindran S, Saikant R, Lakshmi S, Kartik R, et al. Procalcitonin: A promising diagnostic marker for sepsis and antibiotic therapy. J Intensive Care. 2017;5:51. http://doi.org/10.1186/s40560-017-0246-8

6. Farrokhpour MF, Kiani A, Mortaz E, Taghavi K, Farahbod AM, Fakharian A, et al. Procalcitonin and proinflammatory cytokines in early diagnosis of bacterial infections after bronchoscopy. Open Access Maced J Med Sci. 2019;7(6):913-919. http://doi.org/10.3889/oamjms.2019.208

7. Tille P. Bailey and Scott Diagnostic Microbiology. $13^{\text {th }}$ ed. Amsterdam, Netherlands: Elsevier Health Sciences; 2014.

8. Oussalah A, Ferrand J, Filhine-Tresarrieu P, Aissa N, AimoneGastin I, Namour F, et al. Diagnostic accuracy of procalcitonin for predicting blood culture results in patients with suspected bloodstream infection: An observational study of 35,343 consecutive patients (a strobe-compliant article). Medicine. 2015;94(44):e1774.

http://doi.org/10.1097/MD.0000000000001774

9. Kim MH, Lim G, Kang SY, Lee WI, Suh JT and Lee HJ. Utility of procalcitonin as an early diagnostic marker of bacteremia in patients with acute fever. Yonsei Med J. 2011;52(2):276-281. http://doi.org/10.3349/ymj.2011.52.2.276

10. Simon L, Gauvin F, Amre DK, Saint-Louis P and Lacroix J. Serum procalcitonin and C-reactive protein levels as markers of bacterial infection: A systematic review and meta-analysis. Clin Infect Dis. 2004;39(2):206-217. http://doi.org/10.1086/421997

11. Mehanic $S$ and Baljic R. The importance of serum procalcitonin in diagnosis and treatment of serious bacterial infections and sepsis. Mater Sociomed. 2013;25(4):277-81. http://doi.org/10.5455/msm.2013.25.277-281

12. Mahale RP, Rao MR and Shivappa SG. Evaluation of procalcitonin, CRP and blood culture in the diagnosis of neonatal 
sepsis. Int J Curr Microbiol Appl Sci. 2018;7(4):2747-55.

https://doi.org/10.20546/ijcmas.2018.704.3132014

13. Li S, Rong H, Guo Q, Chen Y, Zhang G and Yang J. Serum procalcitonin levels distinguish Gram-negative bacterial sepsis from Gram-positive bacterial and fungal sepsis. J Res Med Sci. 2016;21:39 http://doi.org/10.4103/1735-1995.183996

14. Matha SM, Rahiman SN, Gelbart BG and Duke TD. The utility of procalcitonin in the prediction of serious bacterial infection in a tertiary paediatric intensive care unit. Anaesth Intensive Care. 2016;44(5):607-614.

http://doi.org/10.1177/0310057X1604400505

15. Bassetti M, Russo A, Righi E, Dolso E, Merelli M, D’Aurizio F, et al. Role of procalcitonin in predicting etiology in bacteremic patients: Report from a large single-centre experience. J Infect Public Health. 2020;13(1):40-45 http://doi.org/10.1016/j.jiph.2019.06.003

16. Demirdal T, Sen $P$ and Nemli SA. Diagnostic value of procalcitonin in predicting bacteremia in intensive care unit. Indian J Crit Care Med. 2018;22(2):78-84. http://doi.org/10.4103/ijccm.IJCCM_437_17

17. Leli C, Ferranti M, Moretti A, Al Dhahab ZS, Cenci E and Mencacci A. Procalcitonin levels in gram-positive, gramnegative, and fungal bloodstream infections. Disease Markers. 2015;2015:701480.

https://doi.org/10.1155/2015/701480

18. Cha JK, Kwon KH, Byun SJ, Ryoo SR, Lee JH, Chung JW, et al. Clinical value of procalcitonin for suspected nosocomial bloodstream infection. Korean J Intern Med. 2018;33(1):176-184. https://doi.org/10.3904/kjim.2016.119

19. Yan ST, Sun LC, Jia HB, Gao W, Yang JP and Zhang GQ. Procalcitonin levels in bloodstream infections caused by different sources and species of bacteria. Am J Emerg Med. 2017;35(4):579-583. https://doi.org/10.1016/j.ajem.2016.12.017

20. Leng $Y$, Chen $C$, Zhang $Y$, Luo $C$ and Liu B. Ability of serum procalcitonin to distinguish focus of infection and pathogen types in patients with bloodstream infection. Ann Transl Med. 2019;7(7):135.

https://doi.org/10.21037/atm.2019.03.24

21. Watanabe $Y$, Oikawa N, Hariu M, Fuke R and Seki M. Ability of procalcitonin to diagnose bacterial infection and bacteria types compared with blood culture findings. Int J Gen Med. 2016;9:325-331.

https://doi.org/10.2147/IJGM.S115277

22. Bharath MS, Hiremath RS and Basu A. Role of procalcitonin and C-reactive protein in urinary tract infection diagnosis in adults. Int J Adv Med. 2017;4(2):417-419.

23. Xu RY, Liu HW, Liu JL and Dong JH. Procalcitonin and C-reactive protein in urinary tract infection diagnosis. BMC Urol. 2014;14:45.

https://doi.org/10.1186/1471-2490-14-45

24. Chirouze C, Schuhmacher H, Rabaud C, Gil H, Khayat N, Estavoyer JM, et al. Low serum procalcitonin level accurately predicts the absence of bacteremia in adult patients with acute fever. Clin Infect Dis. 2002;35(2):156-161.

https://doi.org/10.1086/341023

25. Julián-Jiménez A, Gutiérrez-Martín $P$, Lizcano-Lizcano A, López-Guerrero MA, Barroso-Manso Á and Heredero-Gálvez E. Usefulness of procalcitonin and C-reactive protein for predicting bacteremia in urinary tract infections in the emergency department. Actas Urol Esp. 2015;39(8):502-510. https://doi.org/10.1016/j.acuro.2015.03.003

26. Van Nieuwkoop C, Bonten TN, van't Wout JW, Kuijper EJ, Groeneveld GH, Becker MJ, et al. Procalcitonin reflects bacteremia and bacterial load in urosepsis syndrome: A prospective observational study. Crit Care (London, England). 2010;14(6):R206.

https://doi.org/10.1186/cc9328

27. Banach J, Wołowiec L, Rogowicz D, Gackowska L, Kubiszewska I, Gilewski W, et al. Procalcitonin (PCT) predicts worse outcome in patients with chronic heart failure with reduced ejection fraction (HFrEF). Disease Markers. 2018:2018:9542784. https://doi.org/10.1155/2018/9542784

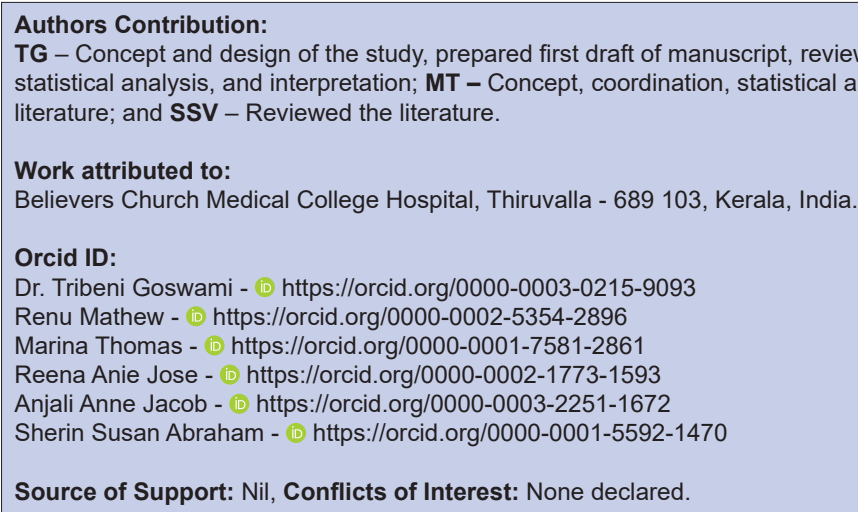

